\title{
Eph Receptor Tyrosine Kinase-Mediated Formation of a Topographic Map in the Drosophila Visual System
}

\author{
Richard Dearborn Jr, ${ }^{1}$ Qi He, ${ }^{2}$ Sam Kunes, ${ }^{1}$ and Yong Dai ${ }^{1}$ \\ ${ }^{1}$ Department of Molecular and Cellular Biology, Harvard University, Cambridge, Massachusetts 02138, and ${ }^{2}$ Department \\ of Biology, City University of New York, Brooklyn, New York 11210
}

\begin{abstract}
Roles for Eph receptor tyrosine kinase signaling in the formation of topographic patterns of axonal connectivity have been well established in vertebrate visual systems. Here we describe a role for a Drosophila Eph receptor tyrosine kinase (EPH) in the control of photoreceptor axon and cortical axon topography in the developing visual system. Although uniform across the developing eye, EPH is expressed in a concentration gradient appropriate for conveying positional information during cortical axon guidance in the second-order optic ganglion, the medulla. Disruption of this graded pattern of EPH activity by double-
\end{abstract}

Eph receptor tyrosine kinases (RTKs) and their ligands, the ephrins, mediate a diverse array of developmental processes, including roles in spatial patterning, cell migration, the demarcation of structural boundaries, and axon guidance (for review, see Flanagan and Vanderhaeghen, 1998; Klein, 2001). Eph receptors are distinguished on the basis of homology and binding to ephrin ligands. EphA receptors bind to ephrinA ligands (linked to the membrane by a glycosylphosphatidylinositol anchor), whereas EphB receptors bind to transmembrane ephrinB ligands. Cellcell signaling through Eph receptors is initiated by binding of the receptor to a membrane-bound ephrin, which promotes receptor dimerization and autophosphorylation of the cytoplasmic domain of the receptor (Davis et al., 1994). On axons, Eph signaling evokes a repulsive response in which growth cones expressing a particular Eph receptor steer away from cells expressing the cognate ephrin (for review, see Orioli and Klein, 1997). Membrane anchorage allows ephrins and Eph receptors to be deployed with the spatial resolution necessary to encode positional information during neural development. In the visual systems of vertebrates, for example, Eph receptors and ephrins are expressed in gradients on retinal ganglion cell (RGC) axons (Cheng et al., 1995; Drescher et al., 1995; Marcus et al., 1996; Braisted et al., 1997; Connor et al., 1998). Genetic studies in the mouse have demonstrated a functional requirement for some Eph/ephrin gradients in retinotopic mapping. For example, the topographic projection of RGCs expressing the EphA8 receptor to the superior colliculus (SC) requires EphA8 (Park et al., 1997) and eph-

Received June 22, 2001; revised Oct. 23, 2001; accepted Nov. 27, 2001.

This work was supported by a Pew Scholars award and National Institutes of Health/National Eye Institute Grants EY10112 (S.K.), EY06688 (Q.H.), and EY07030 (R.D.). We thank the Drosophila Stock Center (Bloomington, IL), Gert Pflugfelder (Wuerzburg, Germany), and Gerry Rubin (Berkeley, CA) for strains and antibody reagents.

Correspondence should be addressed to Dr. Sam Kunes, Harvard University, 7 Divinity Avenue, Room 329, Fairchild Building, Cambridge, MA 02138. E-mail: kunes@fas.harvard.edu.

Copyright (ㄷ) 2002 Society for Neuroscience $\quad 0270-6474 / 02 / 221338-12 \$ 15.00 / 0$ stranded RNA interference or by ectopic expression of wildtype or dominant-negative transgenes perturbed the establishment of medulla cortical axon topography. In addition, abnormal midline fasciculation of photoreceptor axons resulted from the eye-specific expression of the dominant-negative EPH transgene. These observations reveal a conserved role for Eph kinases as determinants of topographic map formation in vertebrates and invertebrates.

Key words: Eph receptor; topographic map; visual system; axon guidance; Drosophila visual system; optic lobe

rinA2, ephrinA5 gradients in the SC (Frisen et al., 1998; Feldheim et al., 2000). In another study, the targeted "knockin" of eph $\mathrm{A} 3$, which disrupted wild-type EphA gradients in the retina, concomitantly disrupted RGC topographic projections to the SC (Brown et al., 2000). These data provide strong evidence for a requirement for Eph/ephrin gradients in neural topographic map formation.

Given the well established roles of Eph receptors in vertebrate visual system development, we decided to investigate whether a Drosophila Eph family member (EPH) might play an analogous role. In the Drosophila visual system, the neurocrystalline array of ommatidial units of the eye is recapitulated in a precise architecture of photoreceptor (R-cell) axon connections in the brain (Meinertzhagen and Hanson, 1993). The R1-R6 photoreceptor axons project retinotopically into the ganglion layer known as the lamina (see Fig. 1b,c), whereas the axons of R7 and R8 photoreceptors project beyond the lamina to the medulla ganglion (see Fig. 1f,i), also in a precise retinotopic map (see Fig. 1b). Connective topography is likewise established by the cortical neurons of the lamina and medulla. In the medulla, neurons arrayed in an outer disk-like cortex project axons in a precise centripetal pattern into a central neuropil (see Fig. $1 b, h$ ). Previous study has suggested that positional target cues are used in establishing visual system connective topography (Kunes et al., 1993). We found that EPH is expressed in a differential pattern on two major developmental axes during the period of axon outgrowth in the eye and optic ganglia and that this graded pattern of EPH activity is required for the establishment of photoreceptor axon and cortical axon topographic maps.

\section{MATERIALS AND METHODS}

Isolation and sequence analysis of eph $c D N A$ clones. Poly $\left(\mathrm{A}^{+}\right)$-selected RNA (Invitrogen, San Diego, CA) from $12 \mathrm{hr}$ embryos was used as template for an oligo-dT-primed reverse-transcription reaction (Sambrook et al., 1989). Degenerate oligos were devised based on a comparison of Dror (Wilson et al., 1993) and EphA3 within the tyrosine kinase domain (IMGQFDHP and TVIQLVGM). The DNA fragments pro- 
duced by PCR amplification were subcloned into pBluescript and sequenced using a T7 Sequenase kit (United States Biochemical, Cleveland, $\mathrm{OH}$ ). Clones bearing homology to EphA3 were used to screen a Drosophila brain cDNA library (Wilson et al., 1993) and an eye disc library (kindly provided by G. Rubin, University of California at Berkeley, Berkeley, CA). Two overlapping cDNAs spanning 3438 base pairs were found to encode a protein, EPH, with homology to vertebrate Eph receptor tyrosine kinases.

Generation of $\mathrm{P}[\mathrm{UAS}-\mathrm{eph}]$ or $\mathrm{P}\left[\mathrm{UAS}-\mathrm{eph}^{\mathrm{DN}}\right.$ ] transgenic animals. A full-length $e p h$ cDNA was modified by PCR to include NotI sites at each end. This NotI fragment was inserted into the transformation vector pUAST (Brand and Perrimon, 1993) to generate $e p h^{+}$. A dominantnegative eph transgene $\left(e p h^{D N}\right)$ lacking residues $675-1035$ was generated using the following PCR primers to place KpnI sites at each end and a stop codon shortly after the conserved juxtamembrane tyrosine phosphorylation sequence: antisense, ggtaccttattctcgagcgaattcct; sense, ggtaccagaatgtcattattaaggaca (start and stop codons are italicized). This PCR fragment was then inserted into the transformation vector pUAST (Brand and Perrimon, 1993). Transformation of Drosophila was performed as described by Rubin and Spradling (1982).

Misexpression of wild-type and dominant-negative eph transgenes. Patterned expression of eph transgenes was accomplished using the UASGAL4 system (Brand and Perrimon, 1993). For flp-out GAL4 experiments, larvae were subjected to heat shock at $37^{\circ} \mathrm{C}$ for $8 \min \left(t u b \alpha_{1}>y^{+}\right.$, $C D 2>G A L 4) 24-36 \mathrm{hr}$ after hatching to induce the expression of an hsFLP transgene. All crosses were grown at $25^{\circ} \mathrm{C}$, and late third-instar larvae were dissected and subjected to immunohistochemical analyses. The following crosses were used: (1) $y, w ; \mathrm{P}\left\{U A S-e p h^{D N}\right\} \mathrm{X} y, w / Y ; \mathrm{P}\{e y-G A L 4\} /$

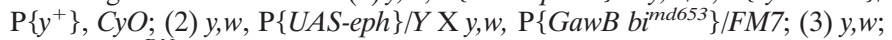
$\mathrm{P}\left\{U A S-e p h^{D N}\right\} \times y, w / Y ; \mathrm{P}\{a p-G A L 4\}, P\{U A S-C D 8:: G F P\} / \mathrm{P}\left\{y^{+}\right\}, C y O$; (4) $y, w, \mathrm{P}\{U A S-e p h\} \times y, w / Y$; $\mathrm{P}\{a p-G A L 4\}, P\{U A S-C D 8:: G F P\} / \mathrm{P}\left\{y^{+}\right\}$, $\mathrm{CyO}$; and (5) $y, h s F L P_{122} ; \mathrm{P}\left\{U A S-e p h^{D N}\right\} \mathrm{X} y, w / Y ; \mathrm{P}\left\{t u b \alpha_{1}>y^{+}\right.$, $C D 2>G A L 4\}, \mathrm{P}\{U A S-C D 8:: G F P\} / \mathrm{P}\left\{y^{+}\right\}, C y O$.

Immunocytochemistry. The spatiotemporal pattern of EPH expression was examined immunocytochemically essentially as described by Kunes et al. (1993) with an affinity-purified polyclonal rabbit antibody raised against a synthetic peptide based on the predicted EPH C terminus (amino acids 950-968, TTRPSPESDGNHILDGQRG; Zymed, San Francisco, CA). The specificity of the affinity-purified EPH antibody used in these experiments was tested on Western blots of protein extracted from late third-instar larval brains (Fig. 1e). The antiserum predominantly recognized an $\sim 110 \mathrm{kDa}$ band (Fig. 1e, lane 2 ), consistent with the predicted size of EPH. This band was not detected with preimmune sera (Fig. 1e, lane 1).

Primary antibodies were used at the following dilutions: polyclonal rabbit anti-EPH, 1:500; goat FITC anti-HRP (Cappel, Cochranville, PA), 1:200; mouse monoclonal antibody 24B10 (anti-Chaoptin) (Fujita et al., 1982), 1:4; and rabbit anti-Repo, 1:500. Secondary antibodies were used at the following dilutions: Cy3-donkey anti-mouse (Jackson ImmunoResearch, West Grove, PA), 1:200; Cy5-goat anti-mouse (Jackson ImmunoResearch), 1:200; HRP-conjugated goat anti-mouse IgG (Jackson ImmunoResearch), 1:100; and Cy5-donkey anti-rabbit (Jackson ImmunoResearch), 1:500. Specimens were viewed on a Zeiss (Thornwood, NY) LSM410 confocal microscope equipped with a krypton-argon laser.

$R N A$ localization by tissue in situ hybridization. In situ hybridization was performed on larval stage specimens by a modification of the method of Tautz and Pfeifle (1989). Probe preparation and hybridization conditions were performed as described by Lehmann and Tautz (1994). To prepare probe template, a $2 \mathrm{~kb} \mathrm{~N}$-terminus $X b a \mathrm{I}$ fragment of $e p h$ was subcloned into the $X b a \mathrm{I}$ site of pBluescript (Promega, Madison, WI), which contains T3 and T7 RNA polymerase recognition sequences for in vitro transcription of RNA. Linearized template was prepared by cutting this construct with either NotI to generate T3 control sense probe or KpnI to generate T7 antisense probe. Probes were labeled with digoxigenin using a Genius kit (Roche Products, Hertforshire, UK) and subsequently developed after incubation with anti-digoxigenin-alkaline phosphatase (AP)-conjugated antibodies. Stained specimens were mounted as described previously (Kunes et al., 1993) and imaged using a Leitz DMRD camera (Leica, Allendale, NJ) and ProgRes digital camera software (Kontron Elektronik)

Western blots and SDS-PAGE. Gel electrophoresis and Western blots were performed on a Bio-Rad (Hercules, CA) Mini Protean II system. Proteins were separated using the discontinuous gel method of Laemmli (1970). For Western blots, SDS-PAGE-separated samples were electro- phoretically transferred to nitrocellulose $(0.2 \mu \mathrm{m}$ pore size $)$ at $100 \mathrm{~V}$ for $1 \mathrm{hr}$ following standard protocols (Towbin et al., 1979). Blots were cut to $\sim 5$-mm-wide strips and incubated for $4 \mathrm{hr}$ at room temperature in BSTN [10\% filtered goat serum (Invitrogen) and 0.3\% Triton X-100 in balanced salt solution (Ashburner, 1989)]. Primary antibody (affinity-purified polyclonal rabbit anti-EPH at 1:500 or preimmune sera at 1:500) was then applied in BSTN for $20 \mathrm{hr}$ at room temperature. The strips were then washed in multiple changes of PBT $(0.3 \%$ Triton X-100, $130 \mathrm{~mm} \mathrm{NaCl}$, $7 \mathrm{mM} \mathrm{Na}_{2} \mathrm{HPO}_{4}$, and $3 \mathrm{~mm} \mathrm{NaH} \mathrm{PO}_{4}, \mathrm{pH}$ 7.4), blocked for $3 \mathrm{hr}$ at room temperature in BSTN, and incubated with secondary antibody (alkaline phosphatase-conjugated goat anti-rabbit IgG, 1:1000; Kirkegaard \& Perry, Gaithersburg, MD) overnight at room temperature. The strips were washed as before in PBT and developed using a Bio-Rad alkaline phosphatase developing kit.

$d s R N A$ interference with eph expression. A full-length eph Not I fragment and the $2 \mathrm{~kb}$ N-terminal $X b a \mathrm{I}$ fragment of eph (both subcloned into pBluescript) were used in dsRNA interference experiments. Linearized template was used to prepare T3 and T7 RNA polymerase-generated single-stranded RNAs using a Genius kit (Roche Products). Equal molar amounts of sense and antisense RNA were mixed together, boiled for 1 $\mathrm{min}$, and allowed to anneal overnight at room temperature in injection buffer $\left(0.1 \mathrm{~mm} \mathrm{NaPO}_{4}, \mathrm{pH} 7.8\right.$, and $\left.5 \mathrm{~mm} \mathrm{KCl}\right)$. Single-stranded RNAs and double-stranded annealed RNAs were examined by agarose gel electrophoresis for confirmation of size and purity before injection. $y w^{67 c 23}$ embryos were collected and processed for injection according to Rubin and Spradling (1982). Embryos were injected with $2 \mathrm{mg} / \mathrm{ml}$ dsRNA under oil.

\section{RESULTS}

\section{Molecular cloning of eph}

The Drosophila eph gene, the sole Eph family member encoded in Drosophila (Adams et al., 2000), was identified by a PCR-based strategy on cDNA isolated from the developing visual system (Fig. 1a) (GenBank accession number AAD30170; for details, see Materials and Methods). The predicted eph gene is identical to the previously reported Dek gene (Scully et al., 1999), with a significant distinction in the predicted site of the N-terminal methionine. The name eph (Eph receptor tyrosine kinase) has been adopted for consistency with the unified nomenclature for Eph family receptors (Eph Nomenclature Committee, 1997) and the Flybase Database of the Drosophila Genome (http://flybase. bio.indiana.edu/). Extracellularly, the predicted EPH polypeptide contains a predicted signal peptide sequence and an $\mathrm{N}$-terminal globular domain adjacent to a cysteine-rich region, which is followed by two regions of similarity to fibronectin type III repeats. A transmembrane domain precedes a conserved juxtamembrane region containing tyrosines that are targets for phosphorylation in other Eph receptors (Holland et al., 1997). The tyrosine kinase domain is highly conserved with other Eph family members. The $\mathrm{C}$ terminus of EPH contains a likely PDZ (postsynaptic density 95/Discs large/zona occludens-1) sequence (TII), which has been shown to target vertebrate Eph receptors to synapses (Doyle et al., 1996; Torres et al., 1998) and a sterile $\alpha$ motif (SAM) domain thought to bind Src homology 2 proteins (Ponting, 1995; Schultz et al., 1997). In Figure 1a, the degree of identity to EPH on a domain-by-domain basis is depicted for two other Eph receptors, EphA3 (mouse) and VAB-1 (Caenorhabditis elegans). The highest degree of homology is found in the kinase domain (72 and $62 \%$, respectively), with greater divergence in the extracellular regions. Although the overall identity of the cysteine-rich region is not high (32\%), 14 cysteine residues along with the relative spacing between these residues are conserved, suggesting that the tertiary structure of this region might be similar with other Eph receptors. Notably, a single ephrin-like protein is predicted to be encoded in the Drosophila genome (Y. Dai, unpublished data) (Adams et al., 2000). The relative identity 
a

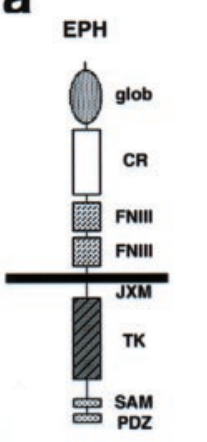

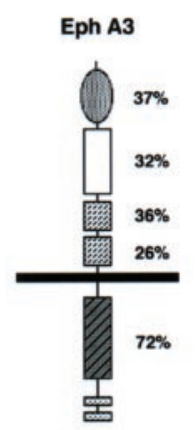

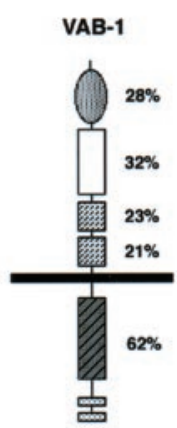

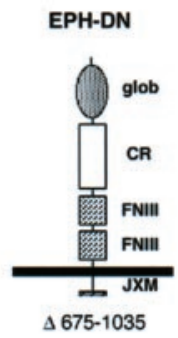

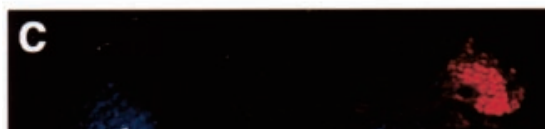

ed
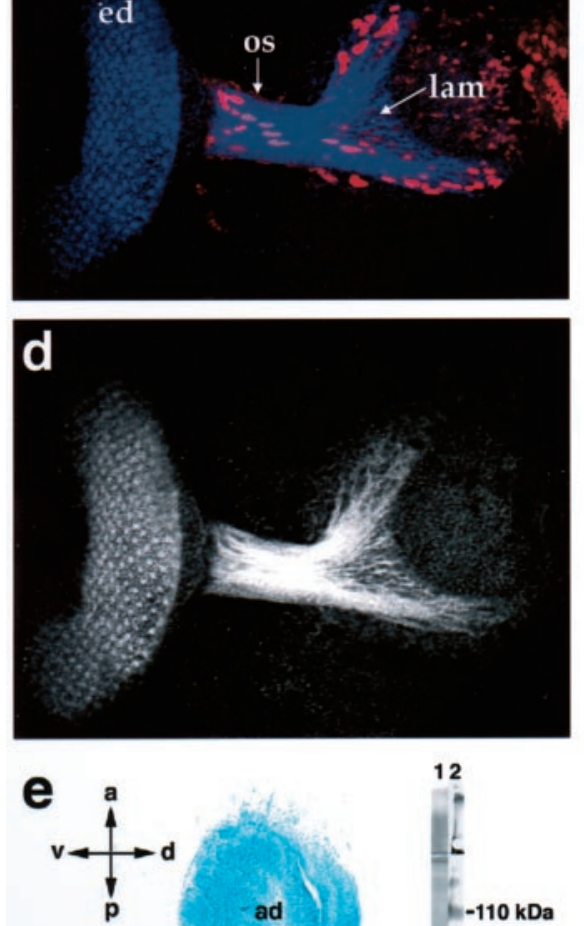

ad

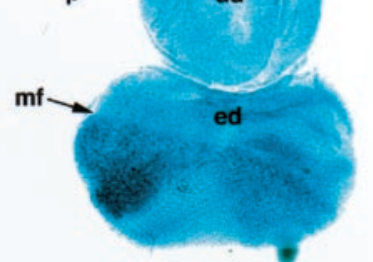

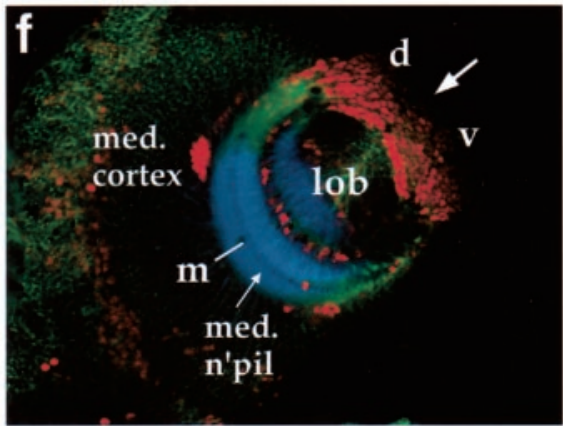
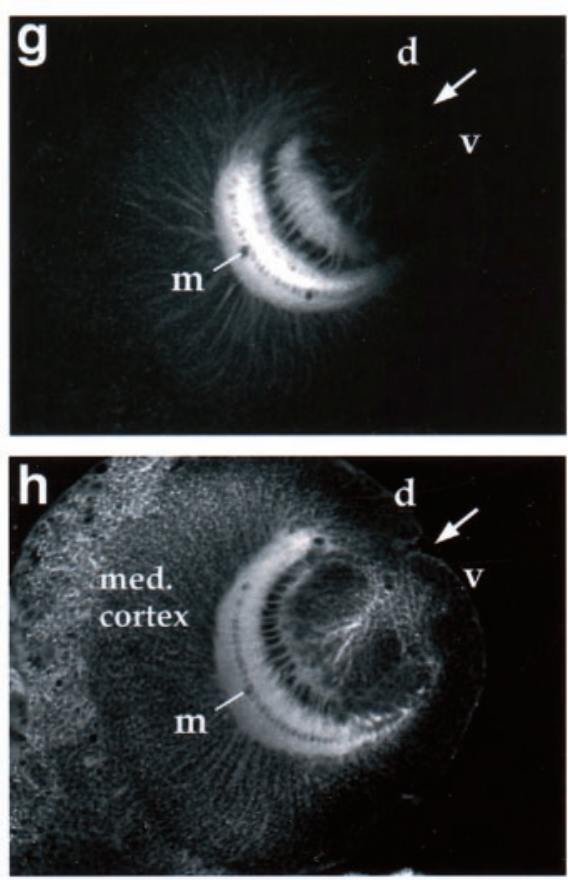

b
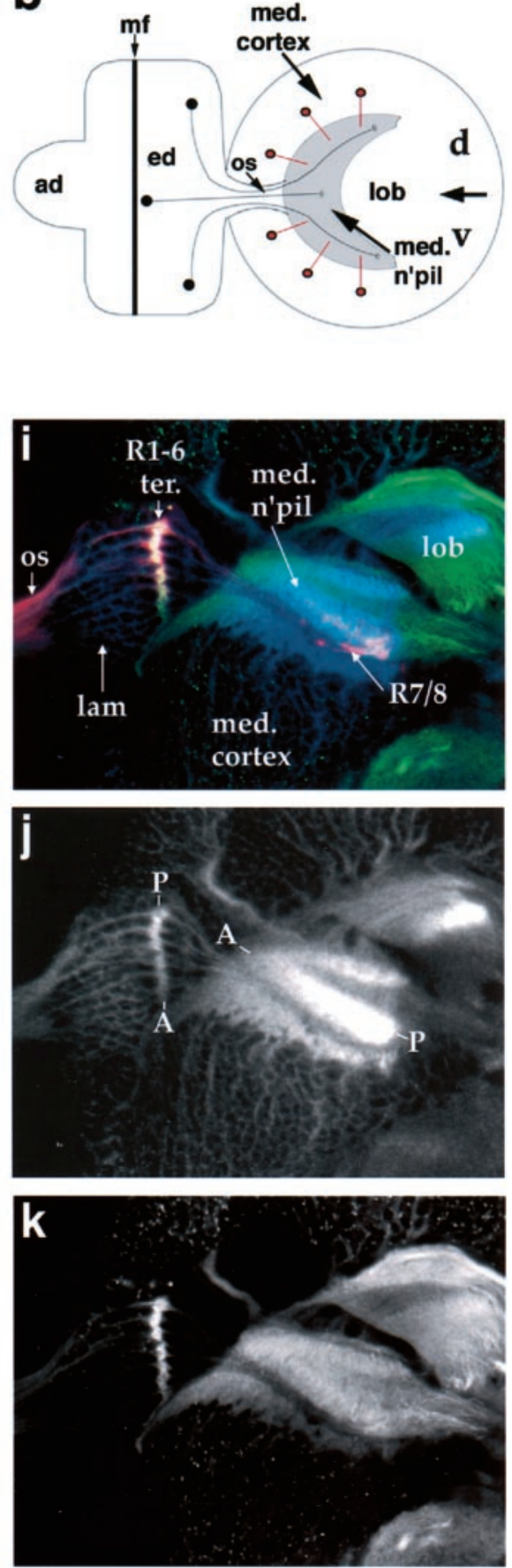

Figure 1. EPH domain structure and distribution in the late third larval instar stage. $a$, Comparison of EPH (nomenclature adopted for consistency with the Flybase Database of the Drosophila Genome) to mouse (EphA3) and C. elegans (VAB-1) Eph receptors. The degree of identity to EPH for each domain of EphA3 and VAB-1 is shown: glob, globular; $C R$, cysteine-rich; FNIII, fibronectin type III repeat; $J X M$, juxtamembrane region; TK, tyrosine kinase; PDZ, PDZ domain; SAM, sterile $\alpha$ motif. The dominant-negative EPH transgene used in these studies is shown to the right of the sequence similarity comparisons; amino acids $675-1035$ are deleted in this construct. $b$, Diagram of the developing eye $(e d)$-antennal $(a d)$ disc from the lateral perspective image shown in $c$ and $f$; axons posterior to the morphogenetic furrow $(m f)$ from dorsal ommatidia project to dorsal optic lobe positions $d$, whereas those from ventral ommatidia project to ventral target sites $v$ in the lamina or more medial medulla regions (shaded crescent). The centripetal projections of cortical cell axons (red) to the underlying medulla are also shown. The midline position is indicated by the black arrow, and the location of the lobula complex $(l o b)$ is indicated. $c$, Photoreceptors in the eye disc (ed) and their axons in the optic stalk (os) and lamina (lam) are strongly stained by anti-EPH antibody (blue) in the late third-instar stage ( $\sim 125 \mathrm{hr}$ AEL). Glia cells in the brain and optic stalk are stained by anti-OMB (red). $d$, Same picture as $c$ but showing EPH staining only. $e$, A bright-field in situ hybridization of a third larval instar eye (ed)-antennal (ad) disc (left side) probed with digoxigenin-labeled eph mRNA. eph is expressed in cells anterior to the morphogenetic furrow ( $m f$ ), consistent with immunostaining patterns. The anteroposterior, dorsoventral orientation of the eye disc is indicated in the top left corner. A Western blot of third larval instar CNS tissue is shown on the right. Lane 2 shows extracts of CNS stained with anti-EPH sera in which a $\sim 110 \mathrm{kDa}$ band, the predicted size for EPH based on its open reading frame, is recognized. This band is not recognized by the preimmune sera (Lane 1), indicating specificity of this antibody for EPH. $f$, A more medial focal plane than $(d)$ showing the medulla neuropil that lies directly beneath the lamina. EPH (blue) is strongly expressed by (Figure legend continues) 
between eph and vertebrate Eph family members does not permit a definitive assignment to either the EphA or EphB classes (Scully et al., 1999).

\section{eph expression in the visual system}

In light of the central role that Eph receptors play in vertebrate visual system development, we focused our attention on the expression of EPH in the developing adult visual system of Drosophila. EPH is prominently expressed in the developing embryonic CNS (Scully et al., 1999) (our unpublished data). In the developing adult nervous system, we found that the most prominent site of EPH expression is the developing eye and optic lobe. EPH is concentrated on photoreceptor cell axons and growth cones. It is also expressed in the developing optic ganglia; in the medulla, cortical cell axons display a positional gradient of $\mathrm{EPH}$ on the prospective dorsoventral axis. Subsequent analysis indicates that a dorsoventral gradient of EPH activity is required for the establishment of medulla cortical axon topography.

Neuronal cell populations of the adult visual system begin differentiation in the late second larval instar $[\sim 80 \mathrm{hr}$ after egg laying (AEL)] after a period of extensive cell proliferation in the optic lobe and eye disc primordia. The eight photoreceptor neurons (R1-R8) in an ommatidial cluster begin their differentiation immediately posterior of the morphogenetic furrow, a wave of differentiation that proceeds in a posterior to anterior direction across the eye disc at this stage. Photoreceptor neurons send their axon projections through an epithelial tube (the optic stalk) to retinotopic destinations in the developing lamina and medulla ganglia (Fig. 1b). Lamina and medulla cortical cell axons also form topographic patterns of connectivity in the lamina and medulla neuropils. eph expression was detected in photoreceptor neurons at the onset of their differentiation in the eye imaginal disc (Fig. 1). eph transcript was localized to the region of differentiating photoreceptor cell clusters immediately posterior of the morphogenetic furrow (Fig. 1e). EPH protein, examined with an affinity-purified polyclonal serum generated against the $\mathrm{C}$ terminus of EPH (Fig. 1e) (for details, see Materials and Methods), was found localized to the membranes of the photoreceptor cell bodies in the eye and concentrated at high levels on photoreceptor cell axons in the optic stalk and developing lamina and medulla ganglia (Fig. $1 d, g, j$ ). In the micrograph shown in Figure $1 d$, EPH antigen is evident in the layer of R1-R6 growth cones at their termination point in the lamina primordium. Significantly, EPH antigen was detected on the most recently arrived R1-R6 growth at the anterior of the lamina field. EPH antigen was also detected on the R7-R8 axons as they continued beneath the R1-R6 termination point toward the medulla (Fig. 1i,j). We carefully examined the possibility of positional differences in $\mathrm{EPH}$ expression in photoreceptor neurons in the eye disc. The distribution of EPH antigen appeared uniform on the dorsoventral axis of the eye field (Fig. 1d, and data not shown) and on the R1-R6 growth cones in their lamina termination layer. EPH expression did display a gradient on the anteroposterior axis, however (Figs. 1j, 2), with a higher level of EPH in older neuronal cell bodies and growth cones (at the posterior of the eye field and lamina termination layer, respectively) (Fig. 1j). However, the significance of this gradient is unclear because it might only reflect an accumulation of antigen with the time after the onset of expression. The resolution of this analysis permits the conclusion that EPH is expressed by both R1-R6 and R7-R8 photoreceptor cell types but did not determine whether distinct subsets of these neurons express EPH in a dynamic pattern. Nonetheless, these observations place EPH in the right place and time to play a role in photoreceptor axon guidance.

Coincident with the expression of EPH in the developing eye, EPH immunoreactivity appears in a temporally and spatially restricted pattern in the cortical cell populations and neuropil structures of the three optic ganglia. In the developing lamina cortex, the onset of EPH expression coincides with the entry of lamina neuron precursors into their terminal cell division, a developmental step that is controlled by the arrival of retinal axons in the lamina target field (Selleck and Steller, 1991). Medial to the lamina is the cortex and neuropil of the medulla, the target destination of R7-R8 photoreceptor axons. Although EPH antigen is detected on the medulla cortical neuron cell bodies, EPH immunoreactivity is strongly localized to medulla axons in the medulla neuropil (Fig. 1g). These cortical cell axons are distinguishable from R7-R8 axons by their failure to express the photoreceptor-specific Mab24B10 antigen. On the dorsoventral axis, EPH expression displayed a symmetrical gradient in the medulla cortex and neuropil, with the highest level of expression at the prospective midline (Fig. $1 g$; compare the distribution of EPH antigen with the relatively uniform anti-HRP antigen in midline versus dorsal and ventral locales in Fig. 1h). EPH levels also displayed an anteroposterior gradient in the medulla neuropil (as revealed in the horizontal perspective in Fig. 1j) (see also Fig. 2). As is the case for the eye and lamina, this posterior (high) to anterior (low) distribution of EPH antigen coincides with temporal posterior to anterior order of medulla neuron differentiation. Thus, the graded distribution of EPH on this axis might simply reflect EPH accumulation in older neurons.

We additionally examined EPH expression at three later time points during the pupal stage. In early pupation (Fig. $2 a-c$ ) [24 hr after puparium formation (APF)], EPH expression is detected in the retina and the three optic ganglia. Interestingly, EPH expression maintains its posterior (high) to anterior (low) gradient first observed in the larval stage for photoreceptor and medulla axons. At a later pupal time point (45 hr APF) (Fig. $2 d-f$ ), EPH antigen on photoreceptor cell bodies in the retina is greatly reduced, whereas high levels of EPH remain within the synaptic neuropils of the lamina, medulla, and lobula. EPH antigen is detected in the lamina cortex and is highly concentrated in the nascent lamina synaptic cartridges in which R1-R6 termini form their synaptic

\section{$\longleftarrow$}

cortical cells (med. cortex) at the prospective dorsoventral midline (indicated by $m$ ) and virtually absent from cells at the most dorsal $(d)$ and ventral $(v)$ regions forming a dorsoventral gradient of expression in the medulla neuropil (med. n'pil). Some of the cortical axons that occupy dorsal and ventral neuropil positions are contributed by OMB-positive neurons (red). $g, h$, Same image as $f$, showing EPH staining only $(g)$ or anti-HRP only $(h) . i$, A view of the optic ganglia from the horizontal perspective at the third-instar larval stage. Photoreceptor axons enter the lateral portion of the brain hemisphere through the optic stalk (os; lateral is to the left). The R1-R6 axons terminate (R1-6 ter) after passing through the lamina cortex (lam), whereas R7-R8 continue medially beyond the R1-R6 termination point into the medulla neuropil (med. n'pil), in which HRP antigen is concentrated (green in $i$ ). As can be seen by comparing $j$ (anti-EPH alone) and $k$ (anti-HRP alone), EPH is concentrated in the older axons the lie at the prospective posterior $(P)$ of the medulla neuropil and lamina (see also Fig. 2). Axons at anterior retinotopic positions $(A$ in $j)$ display less EPH antigen. Axons from the medulla cortex that project into the lobula $(l o b)$ also display a position-specific concentration of EPH antigen at their growth cone termini. 

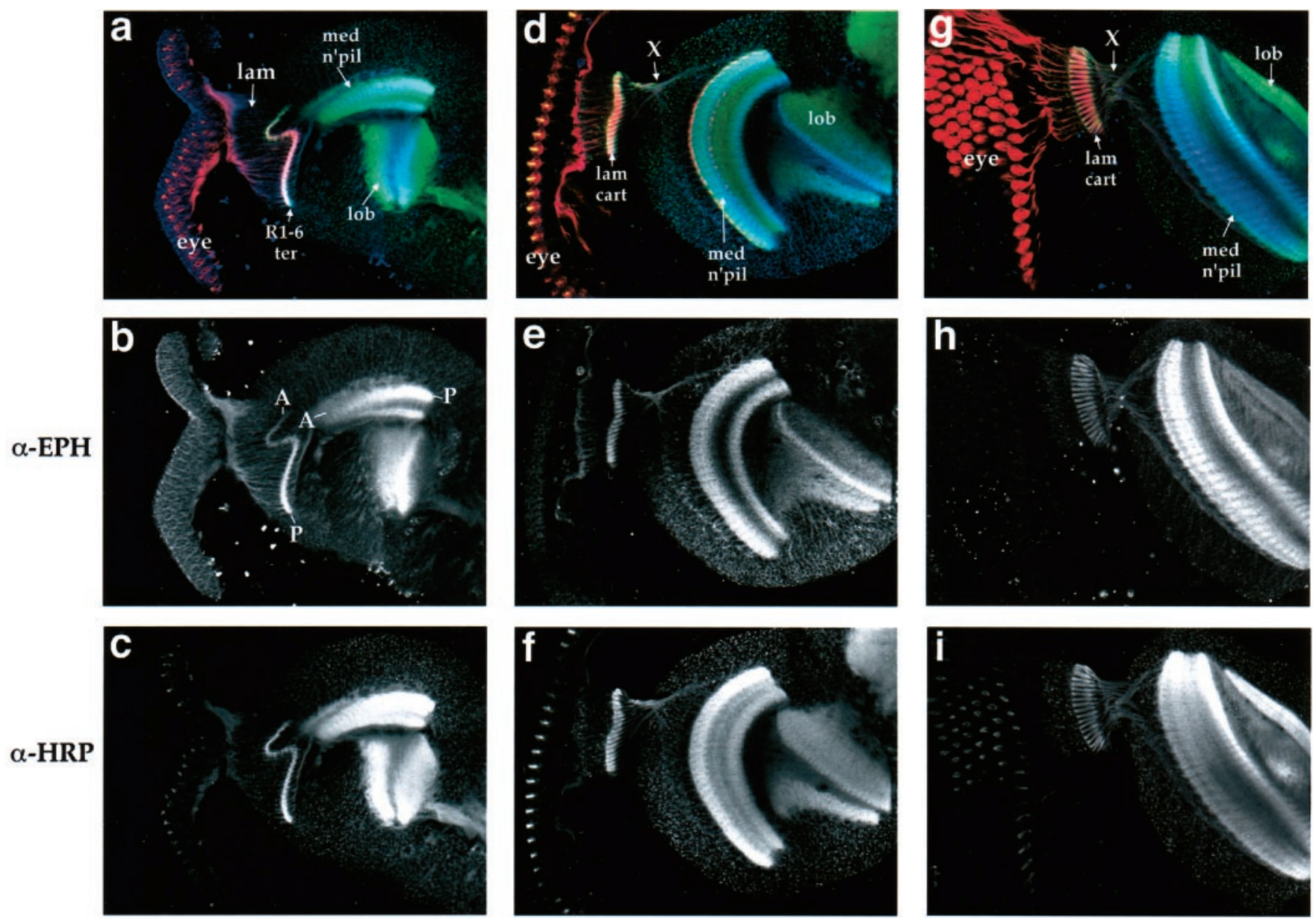

Figure 2. EPH expression during the formation of synaptic circuitry in the visual ganglia. The visual ganglia were isolated at three pupal stage time points $(a-c ; 24 \mathrm{hr}$ APF; $d-f, 45 \mathrm{hr}$ APF; $g-i, 65 \mathrm{hr}$ APF) and stained with anti-EPH antibody (blue in $a, d, g$; alone in $b, e, h)$, anti-HRP ( $g r e e n$ in $a, d$, $g$; alone in $c, f, i)$ and Mab24B10, which specifically stains photoreceptor cells and their axons (red in $a, d, g$ ). As first noted in the late third-instar stage, EPH antigen continues to display a graded concentration on the anterior $(A)$, posterior $(P)$ axis at the early pupal time point $(a-c)$. EPH is most strongly concentrated in the R1-R6 growth cone termini $(R 1-6$ ter $)$ at the prospective posterior of the lamina and cortical cell axonal termini at the prospective posterior of the medulla neuropil (med. n'pil; compare $b, c)$. By $45 \mathrm{hr}$ APF $(d-f)$, EPH antigen is downregulated in the eye and concentrated in lamina synaptic cartridges (lam cart), which begin to form by this time. EPH antigen begins to display a columnar distribution in the medulla neuropil and is localized to a specific layer in the lobula $(l o b)$. By $65 \mathrm{hr}$ APF $(g-i)$, EPH antigen is absent from the eye and concentrated in the synaptic neuropils of the lamina, medulla, and lobula $(h)$. An $X$ denotes the position of the first optic chiasm.

connections. EPH antigen is also concentrated in the medulla neuropil layers in which the R7 and R8 photoreceptor axons form their synaptic connections. In the final time point ( $65 \mathrm{hr}$ APF) (Fig. $2 g-i$ ), EPH antigen is absent from the eye and photoreceptor axons and concentrated in the synaptic neuropils of the lamina, medulla, and lobula. In summary, EPH is initially expressed in both the eye and optic ganglia, concentrated on axons and growth cones, with a graded distribution on the dorsoventral axis of the medulla and anteroposterior axes of the retina, medulla, and lobula. In pupal stage, EPH expression diminishes in the retina and continues in the optic ganglia.

\section{dsRNA interference with eph expression}

As an initial test of EPH function in the development of the visual system, we used double-stranded RNA (dsRNA) interference (RNAi) (Kennerdell and Carthew, 1998; Bhat et al., 1999; Misquitta and Paterson, 1999) to generate possible eph loss-offunction phenotypes. For the majority of loci in plants and worms that have been examined, the phenotypes induced by RNAi have been found indistinguishable from loss-of-function mutations (for review, see Hunter, 2000). Most experience with the use of RNAi in Drosophila has come from analyses at embryonic stages, in which dsRNAs representing $>100$ genes have been found to yield a predicted loss-of-function phenotype (R. Carthew, personal communication). Moreover, the loss of gene activity can continue (but with low penetrance) into the larval and pupal stages (Misquitta and Paterson, 1999). The molecular basis for the specificity of RNAi is now understood and has been studied in both a Drosophila cell-free system (Tuschl et al., 1999), as well as in cultured Drosophila cells (Hammond et al., 2000). We reasoned then that, in light of the difficulty of isolating an eph mutant, RNAi could provide insight into the consequences of eph loss-of-function.

Full-length $e p h^{+}$dsRNA or buffer alone was injected into syncytial stage embryos (for details, see Materials and Methods). No significant difference was observed in the survival rate of embryos injected with dsRNA $(21 \%)$ or buffer alone $(25 \%)$. First-instar hatchlings were grown at $18^{\circ} \mathrm{C}$ and examined immunocytochemically for the expression of EPH antigen at the third- 

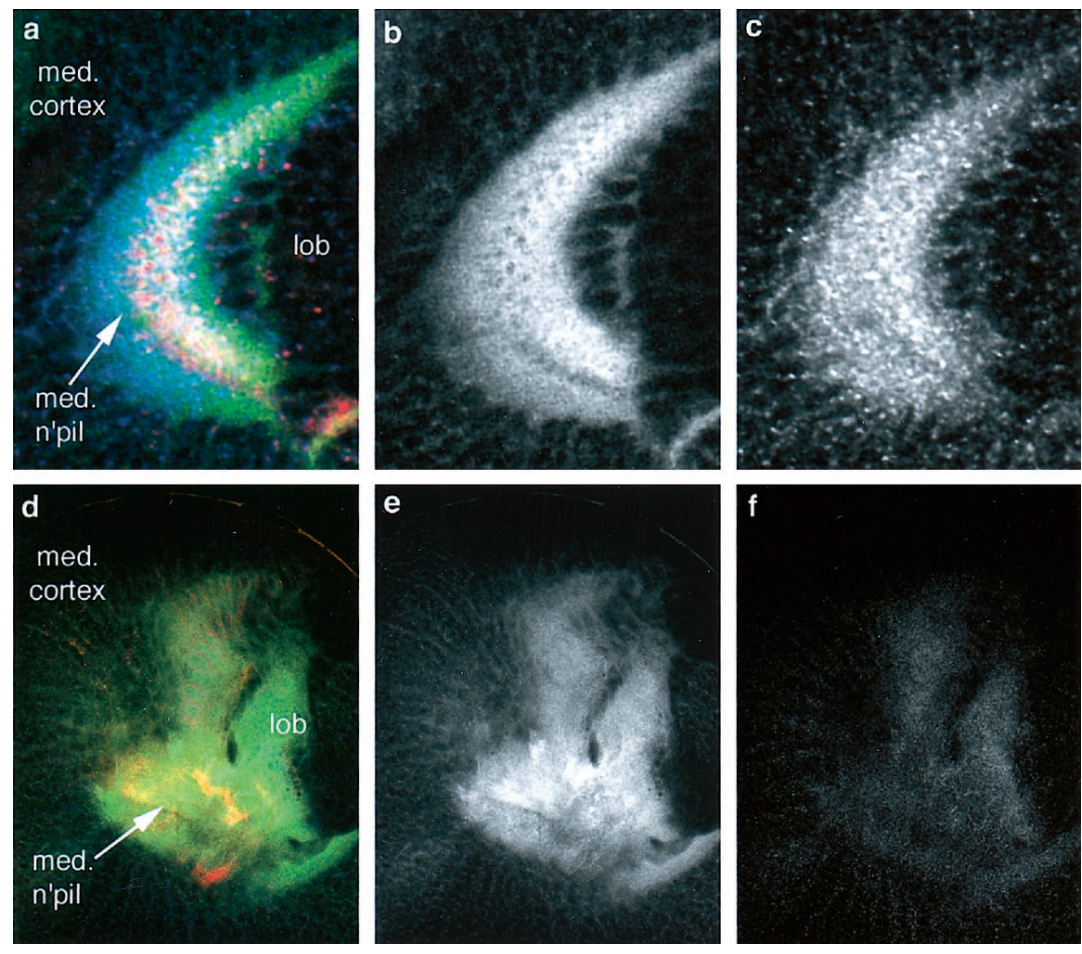

Figure 3. RNAi inhibition of eph expression causes defects in medulla architecture. Animals injected with either buffer alone $(a-c)$ or $2 \mathrm{mg} / \mathrm{ml}$ dseph RNA $(d-f)$ at the syncytial blastoderm embryonic stage were dissected at the late third instar. $a-c$, Lateral view of the medulla neuropil (med. n'pil) of an animal injected with buffer alone showing normal development. The R7-R8 axons (anti-Mab24B10; red in $a$ ) project normally into the neuropil to form a crescent. The larger crescent formed by the centripetal projections of the medulla cortical cell axons (med. cortex) is revealed by anti-HRP staining $(b$; green in $a, d)$. The location of the lobula complex $(l o b)$ is indicated. Anti-EPH staining $(c$; blue in $a$ ) reveals a wild-type dorsoventral gradient of expression. In animals injected with dseph RNA $(d-f)$, dramatic disorganization is evident in the R7-R8 axon projections (red in $d$ ) and medulla cortical cell axon projections ( $e$; green in $d)$ to the neuropil. These defects are associated with a complete loss of EPH immunoreactivity in the brain $(f)$. instar larval stage (120 hr AEL). In 20\% (29 of 140) of the animals derived from embryos injected with eph dsRNA, we observed a significant reduction or complete absence of EPH antigen in the medulla and lobula (Fig. 3, compare $c, f$ ). The loss of EPH expression was correlated with abnormal projections of medulla and lobula cortical axons and defects in photoreceptor axon projections (Fig. 3a,d, red). Defects were observed in all cases in which EPH immunoreactivity was reduced. In these EPH-negative animals, the number and position of medulla cortical cells and their expression of neuronal markers was generally normal (data not shown). The number and position of medulla glia, which may play a critical role in the establishment of cortical axon topography, was also normal in these animals. In a subset of dsRNA-injected animals, EPH antigen was absent only in specific areas of the medulla cortex, as might be expected with the incomplete penetrance of dsRNA-mediated interference. In these cases, the defects in cortical axon projections were correlated with the absence of EPH, arguing that EPH is required autonomously for axon guidance. The effects obtained with dsRNA derived from the full-length eph cDNA were indistinguishable from effects resulting with dsRNA from the region encoding the extracellular portion of EPH, which has no significant homology with other RTKs (data not shown). Reduction of EPH antigen was not observed in animals injected with buffer alone, and optic ganglia development was normal in all cases (Fig. $3 a-c)$. In summary, RNAi-mediated suppression of EPH expression produced cortical axon projection phenotypes consistent with a role for EPH in cortical axon guidance.

\section{Effects of ectopic eph ${ }^{+}$and dominant-negative eph activity on the establishment of visual system connectivity}

As an alternative approach to examining the requirements for EPH in the development of the optic ganglia, we used the $U A S$ GAL4 system (Brand and Perrimon, 1993) to drive the expression of wild-type and dominant-negative eph transgenes. Endog- enously expressed Eph isoforms that lack the kinase domain have been shown to inhibit Eph signaling in vivo (Holmberg et al., 2000). Eph function in vertebrate systems has also been shown to be inhibited by the expression of kinase-inactive Eph isoforms (Xu et al., 1996; Kullander et al., 2001). A similar approach in Drosophila might likewise prove effective in interfering with EPH activity. To this end, we constructed a dominant-negative form of the eph gene $\left(e p h^{D N}\right)$ consisting of normal extracellular and transmembrane domains but lacking most of the intracellular domain, including the kinase, SAM, and PDZ-binding domains (Fig. 1a). The expression of $\mathrm{EPH}^{\mathrm{DN}}$ should result in the expression of a ligand-binding receptor that, in either homodimers or heterodimers with wild-type EPH, would fail to signal. In contrast, misexpression of a wild-type $e p h^{+}$transgene would confer EPH activity on cell populations in which EPH is not normally expressed, thus testing whether the position-specific expression of $\mathrm{EPH}$ is an essential feature of its activity in the establishment of visual system connectivity.

We used the ey-GAL4 driver to drive $U A S$ transgene expression in the anterior portion of the eye disc, including newly formed photoreceptor neuron clusters (Hazelett et al., 1998), as well as in the cortical and glia cell populations of the medulla. Severe defects were produced in the midline projections of photoreceptor and medulla cortical axon projections (Fig. $4 d$, region bracketed by arrowheads) [68\% (63 of 93) of specimens examined] with the expression of $e p h^{D N}$ under ey-GAL4 control. The photoreceptor axons were fasciculated together at the midline of the lamina in a region in which the fascicles would normally separate en route to dorsal and ventral retinotopic positions. These large fascicle bundles often projected to ectopic locations outside of the lamina field (Fig. 4f, region bracketed by arrowheads). Medulla cortical cell axons projected aberrantly only in the midline region of the medulla, the region in which the cortical cells express high levels of EPH. Because of the misrouting of these cortical axons, the medulla neuropil was primarily absent in the midline region, 

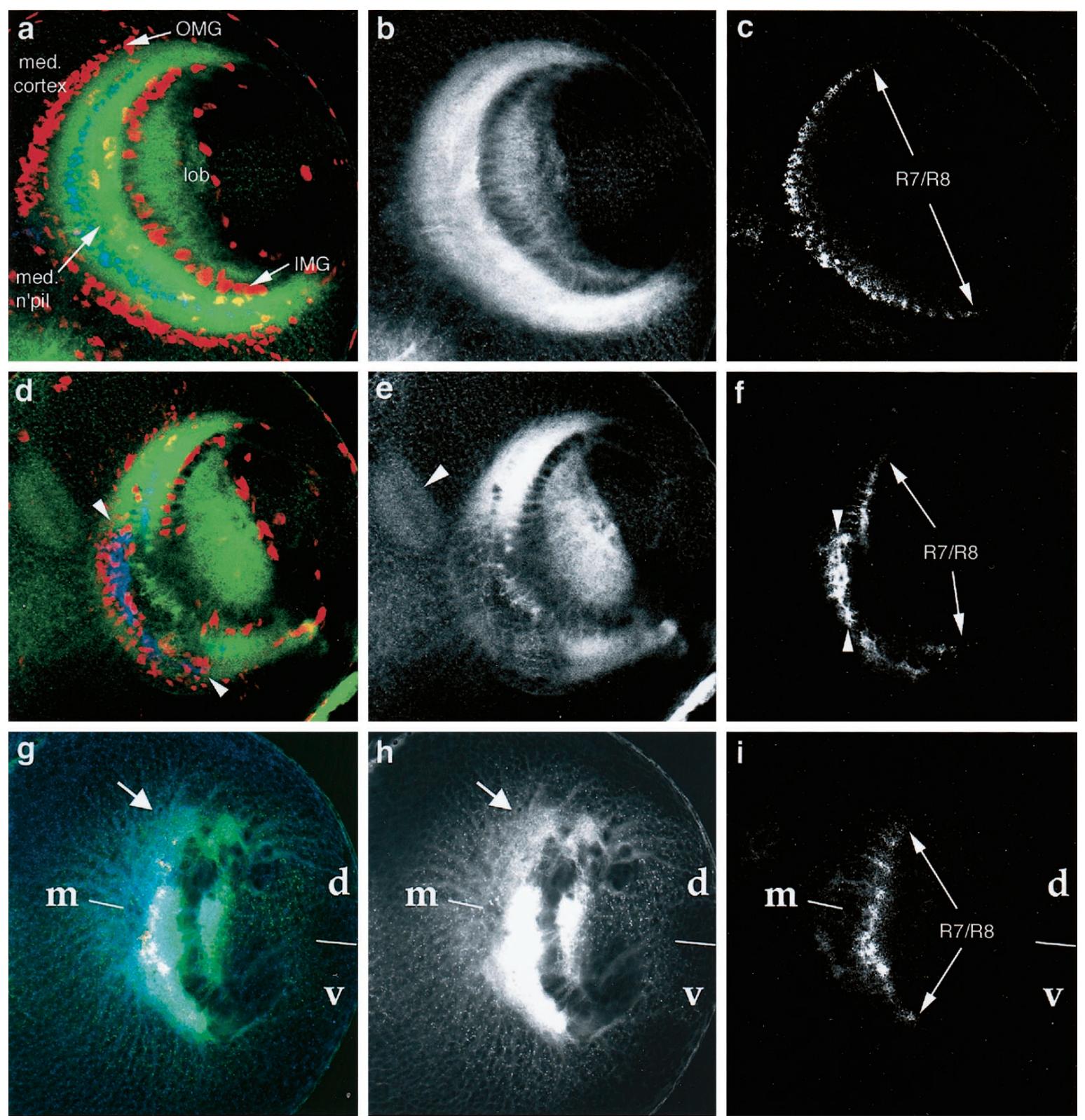

Figure 4. Retinal and cortical cell axons project abnormally when the graded distribution of EPH is disrupted through expression of $e p h^{D N}$ and $e p h^{+}$ transgenes. The ey-GAL4 driver alone does not affect optic ganglia development $(a-c)$. Both cortical cell (med. cortex) axon projections to form the medulla neuropil (med. n'pil; anti-HRP stain; green in $a$; alone in $b$ ) and retinal axon projections (anti-Mab24B10 stain; blue in $a$; alone in $c$; R7-R8) are patterned normally. Medulla glial cells stained with anti-Repo antibodies (red in $a$ ) distribute themselves along the anterior [outer medulla glia $(O M G)$ ] and posterior [inner medulla glia $(I M G)$ ] faces of the medulla normally. The location of the lobula complex $(l o b)$ is indicated. The presence of a single copy of $P\left[U A S\right.$-eph $\left.{ }^{D N}\right]$ under control of the ey-GAL4 driver $(d-f)$ disrupted optic ganglia structures specifically at the midline (region bracketed by arrowheads in $d$ ). The absence of strong anti-HRP staining in the central medulla of these animals is evident in $d$ (green) and $e$ (anti-HRP staining only), in which ectopic anti-HRP staining is detected (arrowhead in $e$ ). Retinal axons project to more anterior positions at the midline (region bracketed by arrowheads in $f$ ) and exhibit abnormal fasciculation (anti-24B10 staining; blue in $d$; shown alone in $f$; R7-R8). Ectopic expression of eph ${ }^{+}$in the pattern of omb $(g-i)$ also disrupted formation of the medulla neuropil. Medulla cortical cell axons (anti-HRP stain; green color in $g$; alone in $h$ ), especially those from dorsal $(d)$ and ventral $(v)$ regions (midline indicated by $m$ ), failed to project in direct centripetal manner into the neuropil, resulting in considerable disorganization (compare region indicated by arrow in $g$ and $h$ with $b$ ). Retinal axon projections (red in $g$; alone in $i$; R7-R8) show some disorganization, albeit less dramatic than what was observed using the $e p h^{D N}$ transgene.

whereas the region devoid of axons filled with glia that would normally border the neuropil (anti-Repo staining; Fig. 4a,d, red). In dorsal and ventral regions, in which EPH is normally not expressed, cortical axons behaved normally.

To address the concern that the dominant-negative EPH receptor might lack specificity for the EPH signaling pathway, we examined whether a wing defect resulting from the expression of $e p h^{D N}$ under the control of the apterous-GAL4 driver (ap-GAL4) (Rincon-Limas et al., 1999) could be suppressed by the coexpression of the $e p h^{+}$transgene. This wing phenotype is readily scoreable, because it is externally visible (data not shown). By increasing the level of functional EPH receptor, the coexpression of the $e p h^{+}$transgene would be expected to suppress this phenotype were $\mathrm{EPH}^{\mathrm{DN}}$ to act specifically in the EPH pathway. The 
additional presence of the $e p h^{+}$transgene did indeed suppress the wing phenotype resulting from the expression of $e p h^{D N}$ under the control of ap-GAL4. Moreover, a rough eye phenotype resulting from the misexpression of the Drosophila Ephrin gene, a candidate ligand for EPH, was suppressed by the coexpression of the $e p h^{D N}$ transgene (Y. Dai and S. Kunes, unpublished observations). These observations, along with the observations in the mouse that introduction of kinase-inactive Eph transgenes (e.g., EphA4) (Kullander et al., 2001) interferes with Eph signaling, permit the conclusion that the defects in midline photoreceptor and medulla cortical axon projections caused by the expression of $e p h^{D N}$ are attributable to specific inhibition of EPH signaling activity.

In contrast to the effects of $e p h^{D N}$ expression on the midline region, ectopic expression of $e p h^{+}$in dorsal and ventral medulla cortical cell populations, in which EPH is not normally expressed, affected the projections of dorsal and ventral cortical axons (Fig. $4 g-i)$. In this case, we used the omb-GAL4 (P[GawB]bi $\left.i^{\text {mas3 }}\right)$ driver, which would express $e p h^{+}$in the pattern of optomotor blind (omb) (Poeck et al., 1993) (Fig. 1c,d,f, red). omb is expressed in dorsal and ventral medulla cortical cell populations (Fig. $1 f g$, domains marked as $d$ and $v$ ), which normally send axons to, respectively, dorsal and ventral regions of the medulla neuropil. These cortical cell populations normally express little or no EPH (Fig. $1 f, g$ ). Omb is also expressed by photoreceptor neurons on the dorsal and ventral edges of the retina, as well as populations of optic lobe glia that eventually migrate into the lamina target field (Fig. 1c,f) (Perez and Steller, 1996; Huang and Kunes, 1998). In $63 \%$ (56 of 89 ) of visual ganglia from animals harboring $o m b-G A L 4$ and $P\left[U A S-e p h^{+}\right]$, defects were observed specifically in the projections of the dorsal and ventral cortical axons (Fig. 4, compare region denoted by arrow in $h$ with the same region in $b$ ). Photoreceptor axons (Fig. $4 i$ ) were also observed to project aberrantly within the medulla region of the omb-GAL4, $P[U A S$-eph $]$ animals. Whether the latter effects were attributable to the disruption of medulla neuropil architecture or to the expression of $e p h^{+}$in dorsal and ventral photoreceptor neurons is not clear.

We also examined the effects of misexpressing the eph ${ }^{D N}$ and $e p h^{+}$transgenes in a specific subset of medulla cortical cells with the use of the ap-GAL4 driver. In these experiments, the axons of cortical cells that express ap-GAL4 were specifically visualized by including the transgene $P[U A S-C D 8:: G F P]$ (Lee and Luo, 1999), which encodes a membrane targeted CD8::GFP fusion protein. In a wild-type animal (Fig. 5a,b), the GFP-labeled axons of ap$G A L 4$-expressing cortical cells project centripetally into the medulla neuropil in a topographically precise manner. In $75 \%$ (55 of 73) of animals harboring ap-GAL4, $P\left[U A S-e p h^{D N}\right]$ and $P[U A S-C D 8:: G F P]$ (Fig. $5 d, e)$, the GFP-labeled axons of midline cortical cells projected aberrantly, whereas those in dorsal and ventral locations typically displayed normal projections. The midline defects included gaps in the cortical axon projections in some areas (Fig. 5e, arrowheads). Bundles of fasciculated cortical cell axons were observed proximal to the midline (Fig. 5e, central arrows). In contrast, cortical cell axons at dorsal and ventral locations only exhibited occasional and less severe navigation defects (Fig. 5e, ventral arrow). Occasional effects in photoreceptor axon projections were also observed in animals with severely defective neuropils (Fig. 5f). Misexpression of eph ${ }^{+}$with the ap-GAL4 driver resulted in a complimentary defect in the medulla. In animals harboring ap-GAL4, $P\left[U A S\right.$-eph $\left.{ }^{+}\right]$, and $P[U A S-C D 8:: G F P]$ (Fig. $5 g, h)$, dorsal and ventral cortical axon projections were most severely affected (Fig. 5h, arrows). These observations are consistent with the notion that the proper development of medulla connectivity depends on EPH activity in a spatially confined domain centered about the midline.

Our final approach to interfering with EPH activity in a position-specific manner made use of the "FLP-out" activated $G A L 4$ driver, $\mathrm{P}\left[t u b \alpha_{1}>y^{+}, C D 8>G A L 4\right]$ (Pignoni and Zipursky, 1997 ) to express $U A S$-eph ${ }^{D N}$ in somatic cell clones (for details, see legend of Fig. 6). In these animals, FLP-mediated recombination between the directly repeated FRT recombination sequences (denoted by $>$ ) in $\mathrm{P}\left[t u b \alpha_{1}>y^{+}, C D 8>G A L 4\right]$ results in somatic clones in which a transcriptional terminator has been removed from between the tubulin $\alpha_{1}$ promoter and GAL4. With the additional presence of the $P\left[U A S-e p h^{D N}\right]$ and $P[U A S-C D 8:: G F P]$ transgenes, GAL4-positive clones (expressing $e p h^{D N}$ ) were labeled with membrane-targeted GFP. In specimens harboring large clones that encompassed most of the developing eye (49 of 61 specimens), photoreceptor axons were usually observed aberrantly fasciculated together at the midline after entering the lamina (data not shown), defects similar to those observed with ey-GAL4 driven expression of $e p h^{D N}$ (Fig. $4 f$ ). Expression of $e p h^{D N}$ exclusively in medulla cortical cells clones (Fig. 6) (12 of 61 specimens) resulted in mistargeting of cortical axons and midline defects in the neuropil. These defects also included, in some cases, photoreceptor axon projection defects at the midline (Fig. $6 c$, region bracketed by arrowheads), perhaps as a consequence of the disruption of medulla neuropil architecture (as was observed in omb-GAL4, $P\left[U A S\right.$-eph $\left.{ }^{+}\right]$specimens). Interestingly, the most striking cortical axon projection defects occurred at clone borders, in which $\mathrm{EPH}^{\mathrm{DN}}$-expressing cells are adjacent to cells that do not express the transgene (Fig. $6 a, b, d$ ). Ventral cortical axons peripherally located relative to the patch of normal optic lobe tissue (Fig. 6d, black, unlabeled area) projected in a normal manner (Fig. $6 d$, arrowhead). However, cortical cell axons nearer to the midline relative to the region of wild-type cells projected in a highly aberrant manner, either at oblique angles (Fig. $6 d$, single arrow) or in fasciculated bundles (Fig. 6d, double arrows). An explanation for these observations would be that, at clone boundaries, the difference in relative levels of EPH activity on neighboring axons is greater. Neurons that normally depend on high levels of EPH activity (at the midline) could be particularly sensitive to the artificial activity gradient imposed by the juxtaposition of normal and $e p h^{D N}$-expressing cells. Cortical cells in more dorsal and ventral locations may be less affected by the clone boundary on account of the lower requirement of $\mathrm{EPH}$ activity observed for these cells in previous experiments. These observations parallel those in vertebrates, in which axons have been shown to be sensitive to relative, not absolute, levels of Eph activity (Hornberger et al., 1999; Feldheim et al., 2000). In summary, these data, like the results described above, are consistent with a requirement for a spatially defined pattern of EPH activity in determining the centripetal pattern of cortical axon projections in the medulla.

\section{DISCUSSION}

Eph RTKs and their ligands, the ephrins, play important roles in directing the formation of topographic patterns of axonal connectivity in vertebrates (Cheng et al., 1995; Braisted et al., 1997; Connor et al., 1998; Hornberger et al., 1999; Brown et al., 2000). Recently, the roles of these receptor-ligand pairs have been investigated in invertebrate systems, in C. elegans (George et al., 1998; Chin-Sang et al., 1999), and in Drosophila melanogaster (Scully et al., 1999). Because the Drosophila genome appears to 

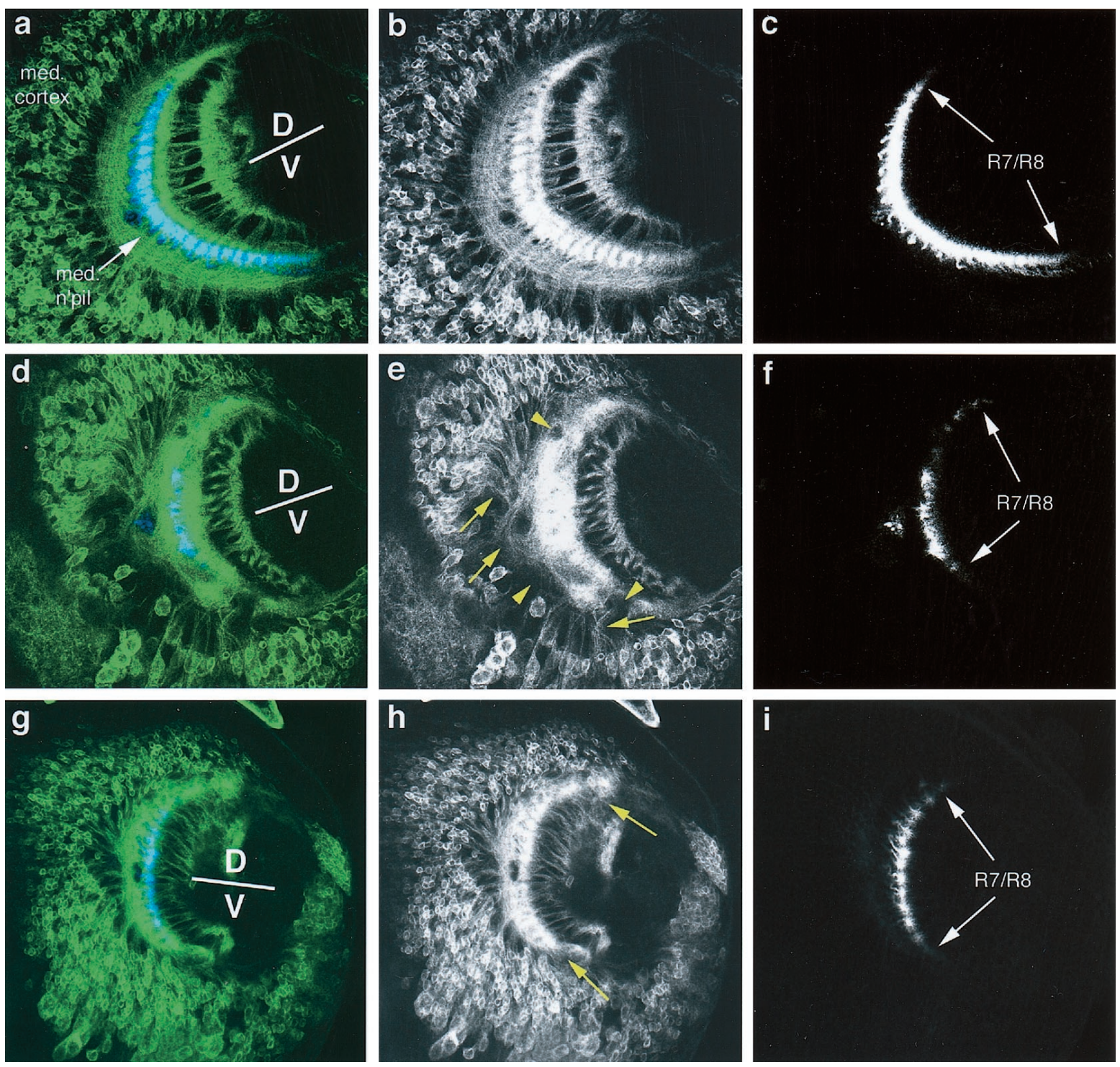

Figure 5. Specific expression of $e p h^{D N}$ in cortical cell populations using the ap-GAL4 driver disrupts the medulla neuropil architecture. Cortical cells bearing ap-GAL4 were labeled with GFP in recombinant animals (see Results); when crossed into eph ${ }^{D N}$ lines, all GFP-positive cells also express the transgene. In animals harboring the $a p-G A L 4$ driver only $(a-c)$, cortical cell (med. cortex) axons project centripetally [dorsal $(D)$; ventral $(V)]$ into the medulla neuropil (med. n'pil), forming a lattice-like meshwork (green in $a$; alone in $b$ ). Retinal axons project topographically into the medulla neuropil, forming a crescent (blue in $a$; alone in $c$; R7-R8). The pattern of axon projections into the medulla neuropil is disrupted in animals harboring both $a p-G A L 4$ and $e p h^{D N}(d-f)$. Cortical cell axons project aberrantly (arrows in $e$ ), creating gaps in the neuropil (arrowheads in $e$ ), which has a fuzzy, undefined quality. In addition, the cortical cells themselves appear to be disorganized, most notably at the midline. Photoreceptor projections ( $f$; R7-R8) exhibit some abnormal midline fasciculation in these animals. The fine structure of the neuropil is also disrupted when $a p-G A L 4$ is used to drive eph in these same cells $(g-i)$. In these animals, the effects are primarily associated with dorsoventral structures (arrows in $h)$ rather than at the midline. Photoreceptor projections (anti-24B10 stain; blue in $g$; alone in $i$; R7-R8) were primarily normal in these animals.

encode only a single Eph family member (Adams et al., 2000) that is prominently expressed in the visual system (Figs. 1, 2), this system may prove uniquely amenable to the genetic analysis of Eph receptor function in the formation of topographic patterns of axonal connectivity. Our observations indicate that Drosophila EPH does play a role in directing axons to topographically appropriate sites within the brain during visual system development. Misexpression of $e p h^{+}$or interference with eph expression or activity disrupted the normal architecture of the optic ganglia, demonstrating that a precise temporal-spatial pattern of EPH activity is important for the development of neuronal connectivity in the Drosophila visual system.

EPH expression coincides spatially and temporally with the differentiation and outgrowth of photoreceptor and cortical cell axons in the developing eye and optic ganglia, respectively (Figs. 1,2). EPH antigen accumulates on the axons and growth cones of these neurons. Interestingly, the level of EPH immunoreactivity varies in a position-specific manner within each tissue. As photoreceptor axons grow into the lamina, EPH antigen is most strongly concentrated on the older photoreceptor growth cones that terminate at the posterior of the lamina. EPH antigen is also most strongly concentrated in the prospective posterior medulla neuropil that contains the axons of the earliest differentiating cortical neurons and R7-R8 photoreceptors. One might suppose that this distribution of antigen reflects the accumulation of EPH with time after the onset of differentiation. However, the obser- 

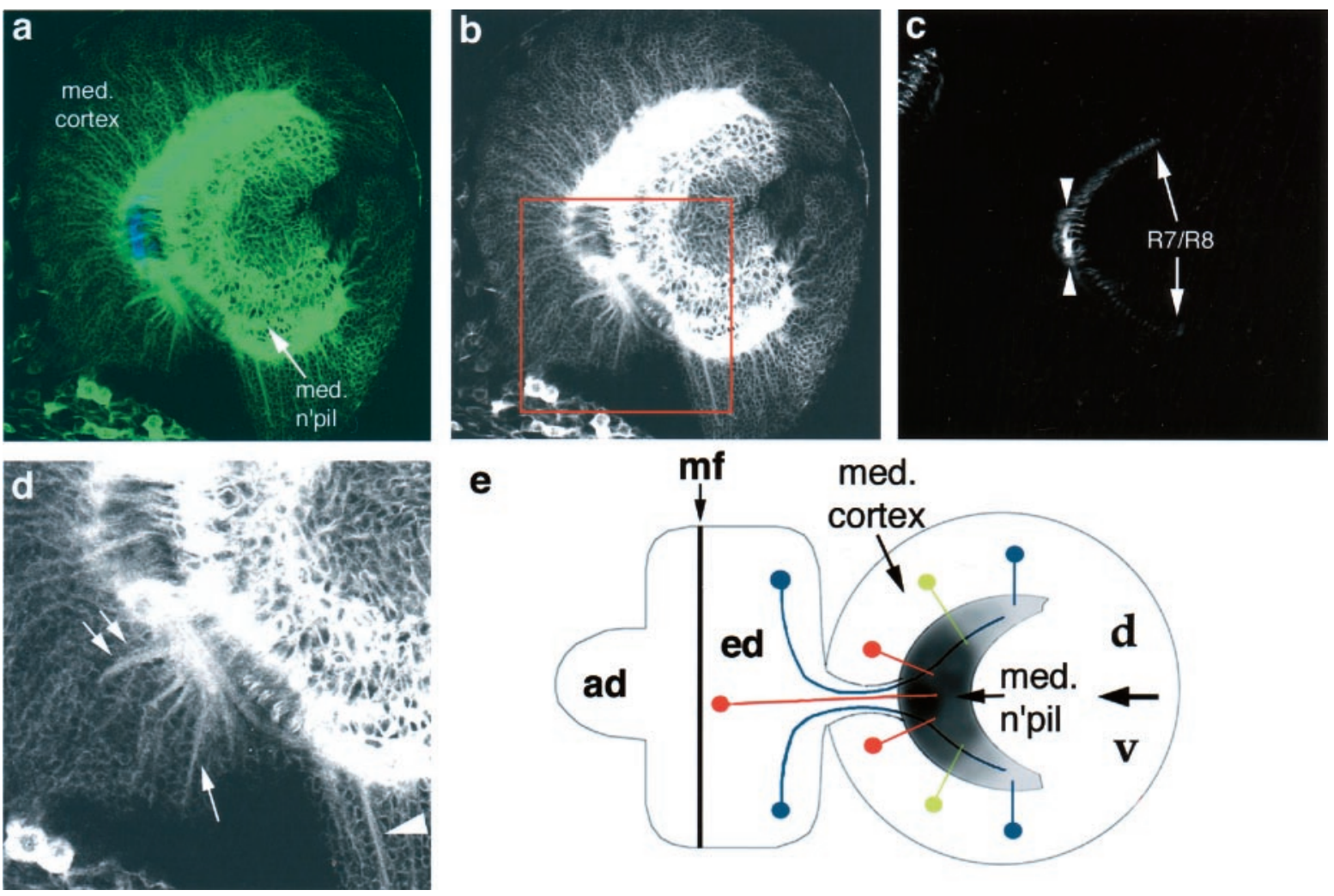

Figure 6. Somatic clones expressing $e p h^{D N}$ indicate that EPH-mediated topographic guidance is important for both photoreceptor and cortical cells. Animals harboring hsFLP ${ }_{122}, \mathrm{P}\{\mathrm{UAS}-\mathrm{CD} 8-\mathrm{GFP}\}, \mathrm{P}\left\{\mathrm{tub} \alpha_{1}>\mathrm{y}^{+}, \mathrm{CD} 2>\mathrm{GAL} 4\right\}$, and $U A S$-eph ${ }^{D N}$ were subjected to a brief heat shock to induce FLP expression. Recombination between the repeated FRT sites (indicated by $>$ ) yields GAL4 ${ }^{+}$clones marked by GFP expression; these clones also express $e p h^{D N}$. Retinal axons (R7-R8) abnormally fasciculated (region bracketed by arrowheads in $c$; anti-24B10 staining; blue in $a$; alone in $c$ ) when the eye tissue was composed of large clones (eye disc not shown). Expression of $e p h^{D N}$ throughout the cortex $(a, d)$ resulted in defects primarily localized to the midline. The higher-magnification view in $d$ of the region indicated in $b$ demonstrates the position-dependent effects of EPH signaling. Cortical cell axon projection defects (abnormal fasciculation and/or topographic projection) were enhanced at borders between wild-type tissue and tissue expressing $e p h^{D N}$ (arrows in $\left.d\right)$. Axon projections dorsoventral to the clone boundaries (arrowhead in $d$ ) were often wild type in appearance. EPH-mediated topographic mapping in the developing visual system is modeled in $e$; antennal disc $(a d)$, eye disc $(e d)$, morphogenetic furrow $(m f)$, medulla cortex $(m e d$. cortex), medulla neuropil (med. n'pil), dorsal $(d)$, and ventral $(v)$ orientations are indicated. The distribution of EPH in the medulla is indicated by the grayscale shading. Medial axons (red cells) of both photoreceptors and cortical cells exhibit the greatest requirement for EPH signaling. Intermediate dorsoventral positions ( yellow cells) require less EPH function, whereas extreme dorsoventrally located cells (blue) require the least degree of EPH signaling.

vation that the anteroposterior gradient on these axons and growth cones persists into the early pupal stage (Fig. 2) suggests that it reflects spatially distinct expression or stability of EPH. EPH also displayed a symmetrical concentration gradient on the dorsoventral axis of the medulla. Cortical neurons at the prospective midline of the medulla expressed the highest levels of EPH (Fig. 1). In analogy with vertebrate Eph family members, the position-specific distribution of Drosophila EPH might reflect a role in the guidance of cortical cell axons to correct topographic positions. Consistent with this model, we found that the single ephrin-like molecule encoded in the Drosophila genome is expressed in a gradient pattern that is complimentary to the EPH dorsoventral pattern in the medulla (Dai and Kunes, unpublished observations). The centripetal trajectories of cortical cell axons might thus rely on a repulsive interaction between EPH-bearing midline growth cones and a dorsoventral localized ephrin ligand (Fig. 6e). The apparently uniform expression of EPH on the dorsoventral axis of the eye does not preclude a role in the dorsoventral guidance of photoreceptor axons. In the chick, the response of retinal growth cones to target-derived ephrin can be modulated by nonuniform coexpression of an ephrin ligand by retinal ganglion neurons (Hornberger et al., 1999).
To gain insight into the role of EPH in the establishment of topographic connectivity, we used double-stranded RNA interference (RNAi) to reduce or eliminate EPH expression. eph dsRNA was injected into syncytial stage embryos to perturb eph expression at the larval time points relevant to axon targeting in the adult visual system. Although there remains some uncertainty with RNAi as a tool for recapitulating loss-of-function phenotypes, recent insight into the molecular underpinnings of RNA interference (Tuschl et al., 1999; Hammond et al., 2000) lend insight into the basis for success with this approach. We enhanced the reliability of RNAi by using unique regions of eph as dsRNA template and by carefully determining the level of EPH antigen in the visual systems of dsRNA-injected animals. Our data reveal that defects in photoreceptor and medulla cortical axon projections are associated with the loss of EPH expression. In the $20 \%$ of specimens that displayed a significant reduction or complete loss of EPH expression, the eye and medulla cortex formed with apparently normal size and cellular organization. The severe defects in medulla neuropil topography observed (Fig. 3) were most consistent with mistargeting of cortical axons. Given the severity of these defects in this target destination for the R7-R8 photoreceptor axons, we cannot conclude that loss of EPH ex- 
pression affected photoreceptor axons directly. The low penetrance of dsRNA-mediated effects $(\sim 20 \%)$ is consistent with previous reports on the effects of embryonic introduction of dsRNA on postembryonic and adult gene expression (Misquitta and Paterson, 1999) (our unpublished data) (Fig. 3). Thus, RNAimediated reduction or elimination of EPH expression indicates that EPH is required for normal optic ganglia formation.

This conclusion was supported and refined by examining the consequences of expressing wild-type $\left(U A S-e p h^{+}\right)$and dominantnegative $\left(U A S-e p h^{D N}\right)$ transgenes in the visual system. In the developing eye, transgene expression was driven in differentiating ommatidial cell clusters with ey-GAL4 (Hazelett et al., 1998) and GMR-GAL4 (Freeman, 1996). Photoreceptor axon fascicles from each ommatidial unit (R1-R8) are normally bundled together as they traverse the optic stalk and then separate on the dorsoventral axis as they turn toward retinotopic destinations in the lamina field. With the expression of $e p h^{D N}$, the photoreceptor axon fascicles located near the midline were affected at the entrance into the lamina, in which they remained bundled together and often projected out of the lamina field (Fig. 4). Axons of dorsally and ventrally located photoreceptors projected to topographically appropriate locations, despite their expression of $e p h^{D N}$. These defects were also observed when the FLP-out GAL4 driver was used to express $e p h^{D N}$ in clones restricted to the developing eye (data not shown). These observations are at odds with those of Scully et al. (1999), who reported GMR-GAL4-driven expression of a putative dominant-negative eph construct did not cause defects in photoreceptor axon pathfinding. However, their construct was made by introducing a single amino acid substitution into the EPH kinase domain to eliminate kinase activity. It is possible that the fasciculation phenotype we observed does not require kinase activity but relies on signaling from other EPH intracellular domains that are deleted in our construct. These observations are consistent with the idea that repulsion mediated by EPH activity is required to separate the axon fascicles as they emerge from the optic stalk. Endogenously truncated isoforms of vertebrate Eph RTKs have been found to promote adhesive interactions when coexpressed with full-length receptors in vitro (Holmberg et al., 2000).

The possibility that the dorsoventral gradient of EPH expression is necessary for the establishment of medulla cortical axon topography was examined by expressing the $e p h^{+}$and $e p h^{D N}$ transgenes in specific cortical cell populations. The omb-GAL4 driver was used to express the $e p h^{+}$transgene in dorsally and ventrally located cortical cell populations that normally express little EPH, thus disrupting the EPH gradient on this axis. This resulted in the disruption of the projections of dorsal and ventral cortical cells. Similarly, when an ap-GAL4 driver was used to misexpress $e p h^{+}$in a subset of cortical cells distributed along the dorsoventral axis, only those cells located in dorsal and ventral locations displayed axon projection defects (Fig. 5). Although the $o m b-G A L 4$ driver would also yield $e p h^{+}$expression at the dorsal and ventral margins of the eye and in a subset of optic lobe glia, the similar outcome resulting with ap-GAL4-driven expression (which is not expressed in either of those cell populations) indicates that cortical cell expression of $e p h^{+}$underlies the axon projection defects. In contrast, ap-GAL4-driven expression of $e p h^{D N}$ resulted in cortical cell axon projection defects at the midline, in which cells normally express the highest levels of EPH. These results are consistent with an interpretation that the requirement for EPH activity is highest at the midline, which coincides with the distribution of EPH along this axis. These observations are also consistent with the activity of the putative ephrin as a growth cone repellent for EPH-positive axons. This ephrin transcript is expressed in a pattern that is complimentary to the EPH pattern on the dorsoventral axis (Dai and Kunes, unpublished observations). More restricted, mosaic expression of the $e p h^{D N}$ transgene in both eye and brain tissues using the FLP-out GAL4 driver further confirms a role for EPH in the formation of both retinotopic and cortical cell topographic projections and suggests that relative levels of EPH activity are critical to the establishment of medulla axon topography, observations consistent with studies performed in the mouse (Hornberger et al., 1999). The role of EPH in mediating topographic map formation in the developing Drosophila visual system is summarized and modeled in Figure $6 e$.

In summary, disruption of wild-type EPH expression and/or activity in both photoreceptor and medulla cortical cells resulted in defects in the axon projections of these cell types consistent with a position-dependent requirement for EPH signaling. Our observations provide the first evidence that the underlying mechanisms directing axons to topographically appropriate sites within the brain during visual system development are conserved in vertebrates and invertebrates, relying on position-specific levels of EPH signaling.

\section{REFERENCES}

Adams MD, Celniker SE, Holt RA, Evans CA, Gocayne JD, Amanatides PG, Scherer SE, Li PW, Hoskins RA, Galle RF, George RA, Lewis SE, Richards S, Ashburner M, Henderson SN, Sutton GG, Wortman JR, Yandell MD, Zhang Q, Chen LX, Brandon RC, Rogers YH, Blazej RG, Champe M, Pfeiffer BD, et al. (2000) The genome sequence of Drosophila melanogaster. Science 287:2185.

Ashburner M (1989) Drosophila: a laboratory manual, p 376. Cold Spring Harbor, NY: Cold Spring Harbor Laboratory.

Bhat MA, Izaddoost S, Lu Y, Cho K, Choi K, Bellen HJ (1999) Discs Lost, a novel multi-PDZ domain protein, establishes and maintains epithelial polarity. Cell 96:833-845.

Braisted JE, McLaughlin T, Wang HU, Friedman GC, Anderson DJ, O'Leary DDM (1997) Graded and lamina-specific distributions of ligands of EphB receptor tyrosine kinases in the developing retinotectal system. Dev Biol 191:14-28.

Brand AH, Perrimon N (1993) Targeted gene expression as a means of altering cell fates and generating dominant phenotypes. Development 118:401-415

Brown A, Yates PA, Burrola P, Ortuño D, Vaidya A, Jessell TM, Pfaff SL, O'Leary DDM, Lemke G (2000) Topographic mapping from the retina to the midbrain is controlled by relative but not absolute levels of EphA receptor signaling. Cell 102:77-88.

Cheng H-J, Nakamoto M, Bergemann AD, Flanagan JG (1995) Complementary gradients in expression and binding of ELF-1 and Mek4 in development of the topographic retinotectal projection map. Cell 82:371-381.

Chin-Sang ID, George SE, Ding M, Moseley SL, Lynch AS, Chisholm AD (1999) The ephrin VAB-2/EFN-1 functions in neuronal signaling to regulate epidermal morphogenesis in C. elegans. Cell 99:781-790.

Connor RJ, Menzel P, Pasquale EB (1998) Expression and tyrosine phosphorylation of Eph receptors suggest multiple mechanisms in patterning in of the visual system. Dev Biol 193:21-35.

Davis S, Gale NW, Aldrich TH, Maisonpierre PC, Lhotak V, Pawson T, Goldfarb M, Yancopoulos GD (1994) Ligands for EPH-related receptor tyrosine kinases that require membrane attachment or clustering for activity. Science 266:816-819.

Doyle DA, Lee A, Lewis J, Kim E, Sheng M, MacKinnon R (1996) Crystal structures of a complexed and peptide-free membrane proteinbinding domain: molecular analysis of peptide recognition by PDZ. Cell 85:1067-1076.

Drescher U, Kremoser C, Handwerker C, Loschinger J, Noda M, Bonhoeffer $F$ (1995) In vitro guidance of retinal ganglion cell axons by RAGS, a $25 \mathrm{kDa}$ tectal protein related to ligands for Eph receptor tyrosine kinases. Cell 82:359-370.

Eph Nomenclature Committee (1997) Unified nomenclature for Eph family receptors and their ligands, the ephrins. Cell 90:403-404.

Feldheim DA, Kim Y-I, Bergemann AD, Frisen J, Barbacid M, Flanagan JG (2000) Genetic analysis of ephrin-A2 and ephrin A-5 shows their requirement in multiple aspects of retinocollicular mapping. Neuron 25:563-574. 
Flanagan JG, Vanderhaeghen P (1998) The ephrins and Eph receptors in neural development. Annu Rev Neurosci 21:309-345.

Freeman M (1996) Reiterative use of the EGF receptor triggers differentiation of all cell types in the Drosophila eye. Cell 87:651-660.

Frisen J, Yates PA, McLaughlin T, Friedman GC, O'Leary DDM, Barbacid M (1998) Ephrin-A5 (AL-1/RAGS) is essential for proper retinal axon guidance and topographic mapping in the mammalian visual system. Neuron 20:235-243.

Fujita SC, Zipursky SL, Benzer S, Ferrus A, Shotwell S (1982) Monoclonal antibodies against the Drosophila nervous system. Proc Natl Acad Sci USA 79:7929-7933.

George SE, Simokat K, Hardin J, Chisholm AD (1998) The VAB-1 Eph receptor tyrosine kinase functions in neural and epithelial morphogenesis in C. elegans. Cell 92:633-643.

Hammond SM, Bernstein E, Beach D, Hannon GJ (2000) An RNAdirected nuclease mediates post-transcriptional gene silencing in Drosophila cells. Nature 404:293-296.

Hazelett DJ, Bourouis M, Walldorf U, Treisman JE (1998) decapentaplegic and wingless are regulated by eyes absent and eyegone and interact to direct the pattern of retinal differentiation in the eye disc. Development 125:3741-3751.

Holland SJ, Gale NW, Gish GD, Roth RA, Songyang Z, Cantley LC, Henkemeyer M, Yancopoulos GD, Pawson T (1997) Juxtamembrane tyrosine residues couple the Eph family receptor EphB2/Nuk to specific SH2 domain proteins in neuronal cells. EMBO J 16:3877-3888.

Holmberg J, Clarke DL, Frisen J (2000) Regulation of repulsion versus adhesion by different splice forms of an Eph receptor. Nature 408:203-206.

Hornberger MR, Dutting D, Ciossek T, Yamada T, Handwerker C, Lang S, Weth F, Huf J, Webel R, Logan C, Tanaka H, Drescher U (1999) Modulation of EphA receptor function by coexpressed EphrinA ligands on retinal ganglion cell axons. Neuron 22:731-742.

Huang Z, Kunes S (1998) Signals transmitted along retinal axons in Drosophila: hedgehog signal reception and the cell circuitry of lamina cartridge assembly. Development 125:3753-3764.

Hunter CP (2000) Gene silencing: shrinking the black box of RNAi. Curr Biol 10:R137-R140.

Kennerdell JR, Carthew RW (1998) Use of dsRNA-mediated genetic interference to demonstrate that frizzled and frizzled 2 act in the Wingless pathway. Cell 95:1017-1026.

Klein R (2001) Excitatory Eph receptors and adhesive ephrin ligands. Curr Opin Cell Biol 13:196-203.

Kullander K, Mather NK, Diella F, Dottori M, Boyd AW, Klein R (2001) Kinase-dependent, kinase-independent functions of EphA4 receptors in major axon tract formation in vivo. Neuron 29:73-84.

Kunes S, Wilson C, Steller H (1993) Independent guidance of retinal axons in the developing visual system of Drosophila. J Neurosci 13:752-767.

Laemmli UK (1970) Cleavage of structural proteins during the assembly of the head of bacteriophage T4. Nature 277:680-685.

Lee T, Luo L (1999) Mosaic analysis with a repressible cell marker for studies of gene function in neuronal morphogenesis. Neuron 22:451-461.

Lehmann R, Tautz D (1994) In situ hybridization to RNA. Methods Cell Biol 44:575-598.

Marcus RC, Gale NW, Morrison ME, Mason CA, Yancopoulos GD (1996) Eph family receptors and their ligands distribute in opposing gradients in the developing mouse retina. Dev Biol 180:786-789.

Meinertzhagen IA, Hanson TE (1993) The development of the optic lobe. In: The development of Drosophila melanogaster (Bate M, Martinez-Arias A, eds) pp 1363-1491. New York: Cold Spring Harbor Laboratory.

Misquitta L, Paterson BM (1999) Targeted disruption of gene function in Drosophila by RNA interference (RNA-i): a role for nautilus in embryonic somatic muscle formation. Proc Natl Acad Sci USA 96:1451-1456.

Orioli D, Klein R (1997) The Eph receptor family: axonal guidance by contact repulsion. Trends Genet 13:354-359.

Park S, Frisen J, Barbacid M (1997) Aberrant axonal projections in mice lacking EphA8 (Eek) tyrosine protein kinase receptors. EMBO J 16:3106-3114.

Perez SE, Steller H (1996) Migration of glial cells into the retinal axon target field in Drosophila melanogaster. J Neurobiol 30:359-373.

Pignoni F, Zipursky SL (1997) Induction of Drosophila eye development by decapentaplegic. Development 124:271-278.

Poeck B, Hofbauer A, Pflugfelder GO (1993) Expression of the Drosophila optomotor-blind gene transcript in neuronal and glial cells of the developing nervous system. Development 117:1017-1029.

Ponting CP (1995) SAM: a novel motif in yeast sterile and Drosophila polyhomeotic proteins. Protein Sci 4:1928-1930.

Rincon-Limas DE, Lu CH, Canal I, Calleja M, Rodriguez-Esteban C, Izpisua-Belmonte JC, Botas J (1999) Conservation of the expression and function of apterous orthologs in Drosophila and mammals. Proc Natl Acad Sci USA 96:2165-2170.

Rubin GM, Spradling AC (1982) Genetic transformation of Drosophila with transposable element vectors. Science 218:348-353.

Sambrook J, Fritsch EF, Maniatis T (1989) Molecular cloning: a laboratory manual, Ed 2, Chaps 10.13-10.24 (Ford N, Nolan C, Ferguson M, eds). New York: Cold Spring Harbor Laboratory.

Scully AL, McKeown M, Thomas JB (1999) Isolation and characterization of Dek, a Drosophila Eph receptor protein tyrosine kinase. Mol Cell Neurosci 13:337-347.

Schultz J, Ponting CP, Hofmann K, Bork P (1997) SAM as a protein interaction domain involved in developmental regulation. Protein Sci 6:249-253.

Selleck SB, Steller H (1991) The influence of retinal innervation on neurogenesis in the first optic ganglion of Drosophila. Neuron 6:83-99.

Tautz D, Pfeifle C (1989) A non-radioactive in situ hybridization method for the localization of specific RNAs in Drosophila embryos reveals translational control of the segmentation gene hunchback. Chromosoma 98:81-85.

Torres R, Firestein BL, Dong H, Staudinger J, Olson EN, Huganir RL, Bredt DS, Gale NW, Yancopoulos GD (1998) PDZ proteins bind, cluster, and synaptically colocalize with Eph receptors and their Ephrin ligands. Neuron 21:1453-1463.

Towbin H, Staehelin T, Gordon J (1979) Electrophoretic transfer of proteins from polyacrylamide gels to nitrocellulose sheets: procedure and some applications. Proc Natl Acad Sci USA 76:4350-4354.

Tuschl T, Zamore PD, Lehmann R, Bartel DP, Sharp PA (1999) Targeted mRNA degradation by double-stranded RNA in vitro. Genes Dev 13:3191-3197.

Wilson C, Goberdhan DC, Steller H (1993) Dror, a potential neurotrophic receptor gene, encodes a Drosophila homolog of the vertebrate Ror family of Trk-related receptor tyrosine kinases. Proc Natl Acad Sci USA 90:7109-7113.

Xu Q, Alldus G, Macdonald R, Wilkinson DG, Holder N (1996) Function of the Eph-related kinase rtk1 in patterning of the zebrafish forebrain. Nature 381:319-322. 